\title{
АНАЛИЗ ИНДУСТРИИ ДЕЛОВОГО ТУРИЗМА РОССИИ: ФОРМИРОВАНИЕ СТРАТЕГИЧЕСКИХ ПОЛЕЙ ДЕЯТЕЛЬНОСТИ КОМПАНИИ
}

\section{ANALYSIS OF THE RUSSIAN BUSINESS TOURISM INDUSTRY: FORMATION OF STRATEGIC FIELDS OF THE COMPANY'S ACTIVITY}

\section{O. Ergunova E. Okhrimenko T. Lukashenok}

Summary. In the article, the authors consider the features of the formation of strategic fields of activity of the International Business Center Corporate Travel company. The specifics of the provision of professional services for the customer service of the business segment in Russia are outlined. The current position of IBC Corporate Travel in the market has been determined. A detailed analysis of the strategic fields of the company's activities has been carried out, which made it possible to present and justify the strategic planning of the company's activities in providing services in the business tourism industry.

Keywords: business tourism, strategic fields of activity, ibc Corporate Travel, international cooperation, competitiveness.
Д еловой туризм в настоящее время является наиболее прибыльным сегментом туристской индустрии. Актуальность темы исследования дается трудами многих ученых. Так, А. Хакан [7], В.В. Евсеев [3] в своих трудах исследуют российский рынок делового туризма и процессы глобализации. Анализ вопросов конкурентоспособности России на мировом рынке делового туризма рассматривают П.И. Ананченкова [1], Л.М. Капустина [4], К.Ф.Фам [6], и др. Опыт развития событийного туризма в РФ и за рубежом рассмотрены в трудах ученых Т.Б. Климовой, Е.В. Вишневской [5].

На современном этапе индустрия делового туризма России является важнейшей составляющей для эффективного развития внешнеэкономических связей.

В связи с обозначенной темой, авторы считают необходимым акцентировать внимание на особенность формирования стратегических полей деятельности компании International Business Center Corporate Travel
Ергунова Ольга Титовна

К.э.н., дочент, Уральский государственный экономический университет (2. Екатеринбург) ergunova-olga@yandex.ru

Охрименко Елена Ивановна

К.п.н., дочент, Уральский государственный экономический университет (2. Екатеринбург) oelenai@yandex.ru

Лукашенок Татьяна Рудольфовна

К.э.н., доцент, Уральский государственный экономический университет (2. Екатеринбург) tanalukas@mail.ru

Аннотация. В статье авторами рассмотрены особенности формирования стратегических полей деятельности компании International Business Center Corporate Travel. 06означена специфика предоставления профессиональных услуг по обслуживанию клиентов бизнес-сегмента в России. Определена текущая позиция IBC Corporate Travel на рынке. Проведен детальный анализ стратегических полей деятельности компании, позволивший представить и обосновать стратегическое планирование деятельности компании по предоставлению услуг в индустрии делового туризма.

Ключевые слова: деловой туризм, стратегические поля деятельности, IBC Corporate Travel, международное сотрудничество, конкурентоспособность.

(далее - IBC СТ), являющейся консолидатором услуг по организации деловых мероприятий любого масштаба, и имеющей сеть филиалов в крупнейших городах Российской Федерации (Москва, Краснодар, Екатеринбург, Новосибирск, Владивосток) [2]. Следует отметить, что IBC СТ специализируется на предоставлении услуг в сфере делового туризма (бронирование ж/д и авиабилетов, проживание, трансферные услуги, визовое сопровождение и т.д.) и организации мероприятий (круглые столы, конгрессы, выставки, выездные совещания и другие корпоративные события). IBC СТ имеет структуру холдингового типа, включающую несколько компаний, каждая из которых работает на одном из сегментов туристического рынка [9].

Одной из особенностей компании является круглосуточная поддержка клиентов в режиме 24/7. Работая в том же часовом поясе, что и клиенты, компания в разы ускоряет бронирование гостиниц, авиа и железнодорожных билетов, обеспечивает выгодные условия проживания и проведения различных мероприятий. 
Глобальным партнером IBC CT является международная компания Hogg Robinson Group (HRG). Таким образом, компания IBC СТ обслуживает корпоративных клиентов - мировых лидеров.

Стоит отметить, что IBC СТ ежегодно становится лауреатом различных премий в рамках своей индустрии, при этом с целью поддержания ведущих позиций целесообразно определить следующие приоритетные направления развития компании:

- укрепление позиций в действующих регионах;

- дальнейшая экспансия деятельности, как на территории РФ, так и за рубеж;

- обеспечение надежных финансовых показателей;

- внедрение новых IT продуктов и бизнес-решений на рынок.

Клиентоориентированность, качество оказываемых услуг, развитие и обучение действующего персонала, а также укрепление команды за счет привлечения успешных представителей индустрии делают компанию конкурентоспособной на мировом рынке. С целью увеличения охвата рынка компания осуществляет значительные инвестиции в модернизацию, интегрируется с другими игроками рынка, производит поиск наиболее интересных предложений, как для клиентов, так и для перспективных кандидатов.

Обеспечение безопасных, комфортных и качественных услуг для корпоративных заказчиков осуществляется с учетом следующих принципов работы:

- инновационный подход к развитию бизнеса, непрерывные разработки и внедрение лучших технологических решений в управлении деловыми поездками;

- предоставление максимально полного комплекса высококачественных туристических услуг от профессионалов в области делового туризма;

- индивидуальный подход к каждому корпоративному клиенту, персонализированный сервис для каждого делового путешественника;

- сокращение расходов и экономия времени клиента на оформление поездок;

- постоянное совершенствование системы обслуживания, согласно высоким требованиям мировых стандартов качества;

- постоянное расширение ассортимента услуг.

Компания следует также принципам социальной ответственности и старается придерживаться лучших мировых стандартов в области организации деловых путешествий и мероприятий.

Показатель выручки компании IBC СТ неуклонно растет, как в разрезе каждого филиала компании, так и в целом по компании.
Невзирая на сложную экономическую ситуацию в стране, компании удается показывать значительный ежегодный рост финансовых показателей. Основными факторами данной тенденции являются:

- большой портфель оказываемых услуг;

- широкое географическое покрытие (6 филиалов в РФ);

- международное сотрудничество (основной партнер - HRG);

- профессиональный менеджмент;

- разработка и внедрение новых IT (Information Technology) решений.

Так как компания IBC CT входит в холдинг IBC Service Network (SN) и является лишь частью портфеля, это позволяет обеспечить стабильные финансовые показатели и получить необходимые денежные средства для дальнейшего развития.

Значительным фактором роста явилось открытие трех новых филиалов:

- г. Санкт-Петербург и г. Владивосток - 2012 г.;

- г. Краснодар - 2013 г.

Это позволило занять новые ниши на рынке делового туризма и заявить «о себе» не как о региональной компании, а как об игроке федерального уровня.

IBC CT ведет активную работу с поставщиками услуг (гостиницы, трансферные компании, авиакомпании, конференц-площадки и т.д.). К настоящему моменту подписано более 7000 прямых договоров с отелями на территории РФ, а также заключены партнерские соглашения с международными интеграторами (Островок, АкамедСервис, Хотелбук и т.д.), что позволяет осуществлять выгодную и клиентоориентированную деятельность по всему миру. Одним из главных преимуществ компании является наличие значительного штата собственных разработчиков (две команды IT г. Москва, г. Екатеринбург), благодаря чему становится возможным вести разработку сразу нескольких продуктов и своевременно выпускать их на рынок.

Разделение всего рынка сбыта услуг компании на стратегические поля деятельности (далее - СПД) позволяет определить текущую позицию IBC СТ на рынке и провести дальнейший анализ и представить стратегическое планирование деятельности компании.

Исторически компания имеет уральские корни, но к настоящему моменту работа построена таким образом, что услуги оказываются на всей территории РФ. Данный фактор является неоспоримым конкурентным преимуществом. Также компания имеет серьезные стратегические планы по дальнейшему развитию и вы- 
Таблица 1. Стратегические поля деятельности компании IBC Corporate Travel (составлено авторами по: [9])

\begin{tabular}{ll|l|l|l|l|l|l|}
\multirow{2}{*}{$\begin{array}{l}\text { Предоставляемые } \\
\text { услуги }\end{array}$} & Клиенты & Москва & Урал & Сибирь & Юг & $\begin{array}{l}\text { Северо- } \\
\text { Запад }\end{array}$ & Дальний Восток \\
\cline { 2 - 9 } & + & + & + & + & + & + \\
\hline Отели & + & + & + & + & + & + \\
\hline Трансферы & + & + & + & + & + & + \\
\hline Авиаперелеты & + & + & + & + & + & + \\
\hline Ж/д билеты & + & + & + & & & + \\
\hline Организация мероприятий & + & СПД 1 & СПД 2 & СПД 3 & СПД 4 & СПД 5 & СПД 6 \\
\hline № СПД & & & & & + \\
\hline
\end{tabular}

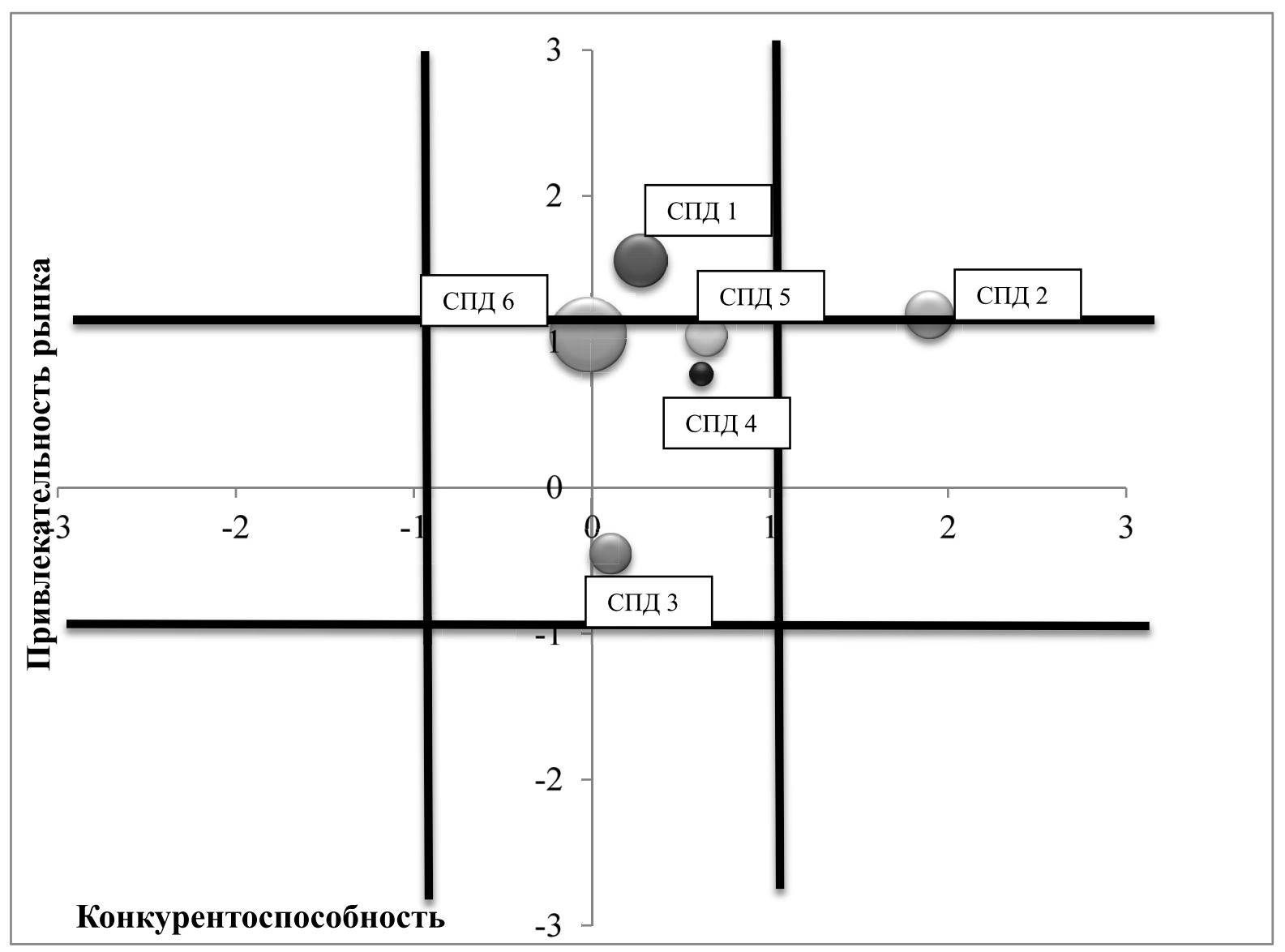

Рис. 1. Матрица МакКинзи (составлено авторами по: [8])

ходу на рынки Китая и Казахстана. Исходя из этого, при определении стратегических полей деятельности были приняты географические критерии сегментирования рынка.

В ходе анализа авторами были выделены следующие СПД:

- СПД 1 - Рынок Центрального Федерального Округа;
- СПД 2- Рынок Урала;

- СПД 3-Рынок Сибири;

- СПД 4 - Рынок Южного Федерального Округа;

- СПД 5 - Рынок Северо-Западного Федерального Округа;

- СПД 6 - Рынок Дальнего Востока (таблица 1).

Каждое выделенное СПД удовлетворяет потребности ограниченной целевой группы клиентов. Каждое 
стратегическое поле деятельности может самостоятельно существовать и имеет свою собственную стратегию.

При формировании СПД целесообразно учитывать следующие признаки рынка:

- наличие на рынке федеральных и региональных клиентов;

- наличие конкурентов и одинаковая доступность проникновения на рынок;

- наличие необходимой для обеспечения деятельности СПД инфраструктуры;

- законодательная и административная возможность предоставления практически всего портфеля оказываемых услуг на территории каждого СПД.

После формирования основных стратегических полей деятельности компании IBC СТ был произведен выбор качественных факторов, которые характеризуют рыночную привлекательность и конкурентоспособHOCTь.

Для более точного определения позиций компании IBC CT на рынке следует обратиться к построению матрицы Мак-Кинзи (рисунок 1), что позволит разработать предварительные рекомендации развития стратегических полей деятельности.

Матрица МакКинзи показывает, что СПД 2 (Урал) находится в позиции лидера. С целью сохранения текущих позиций компании необходимо осуществлять инвестиции для умножения прибыли, концентрировать усилия на поддержание эффективности.

СПД 5 (Северо-Запад) и СПД 4 (Юг) находятся в промежуточной позиции, в которой целесообразно сконцентрировать инвестиции на направлениях с высокой доходностью и относительно низкой степенью риска.

СПД 1 (Москва) характеризуется стадией развития, которая сравнима с позицией растущего лидера и требует тактики избирательных инвестиций и работы над уязвимыми вопросами.

СПД 3 (Сибирь) и СПД 6 (Дальний Восток) занимают пограничные позиции, требующей больших усилий по развитию компаний.

Анализ деятельности компании с использованием матрицы МакКинзи позволит выработать стратегические направления развития филиалов компании. Выше были описаны особенности направления развития для каждого филиала, при этом компании в целом необходимо руководствоваться следующими рекомендациями:

- осуществлять мероприятия по поддержанию и повышению конкурентоспособности на рынке мирового делового туризма;

- сконцентрировать инвестиции в высокоэффективных направлениях с учетом особенностей по каждому филиалу;

- разрабатывать долгосрочные стратегические планы по дальнейшему развитию и выходу на новые рынки;

- развивать комплексный подход и персонализированные программы в сопровождении клиентов;

- повышать уровень комфорта и возможности использования новейших цифровых технологий для клиентов.

Проведенное исследование показало, что каждое выделенное стратегическое поле деятельности компании удовлетворяет потребности ограниченной целевой группы клиентов, может самостоятельно существовать и имеет свою собственную стратегию. Особенность формирования и анализ стратегических полей деятельности компании, представленные в исследовании, позволят компаниям упрочить свои позиции на привлекательных сегментах рынка, более четко представлять собственную стратегию развития, поддерживать свои сильные качества, а также повысить привлекательность и конкурентоспособность на рынке делового туризма.

\section{ЛИТЕРАТУРА}

1. Ананченкова П.И. Туристический имидж дестинации (на примере Азербайджанской республики) / П.И. Ананченкова, М.Ю. Кузнецов // Этносоциум и межнациональная культура, 2017. — № 7 (109). — С. 152-157.

2. Боголюбов В.С., Боголюбова С.А., Карпова Е.Г. Мегаполис как центр развития конгрессно-выставочной деятельности и дестинации делового туризма // Актуальные проблемы развития индустрии гостеприимства: сборник научных статей XVI Международной практической конференции.2021.- - . 93-99.

3. Евсеев В.В. 25 лет Содружеству Независимых Государств: некоторые итоги и возможные перспективы / В.В. Евсеев, Д.В. Харитонова // Научно-аналитический журнал 0бозреватель — Observer, 2017. — № 2 (325). — С. 17-34.

4. Капустина Л.М. Конкурентоспособность стран на мировом рынке туристических услуг [текст]: [монография] / Л.М. Капустина, В.В. Вязовская; М-во образования и науки Рос. Федерации, Урал. гос. экон. ун-т. — Екатеринбург, 2017. — 166 с. 
5. К Климова, Т.Б., Вишневская Е.В. Опыт развития событийного туризма в РФ и за рубежом / Науч. результат. Сер. Технология бизнеса и сервиса. 2014. 一 Т. 1, № 1. - С. 35-41

6. Фам К.Ф. Анализ основных факторов, повлиявших на экономическую ситуацию в РФ в 2015-2016 годах / К.Ф. Фам, М.П. Лазарев // Экономика и бизнес: теория и практика. - 2017. — № 4-2.—C. 109-112.

7. Хакан А. Турецко-российский кризис в 10 вопросах / А. Хакан // ИноСМИ.ру [Электронный ресурс]. - 2016 — Режим доступа: https://inosmi.ru/ politic/20160201/235224552.html.

8. Центр раскрытия корпоративной информации [Электронный ресурс].—Режим доступа: http://www.e-disclosure.ru/\#.

9. IBC Corporate Travel // Официальный сайт компании IBC Corporate Travel [Электронный ресурс].— Режим доступа: http://ct.ibc.ru/ru.

○ Ергунова Ольга Титовна ( ergunova-olga@yandex.ru ),

Охрименко Елена Ивановна ( oelenai@yandex.ru ), Лукашенок Татьяна Рудольфовна ( tanalukas@mail.ru ).

Журнал «Современная наука: актуальные проблемы теории и практики»

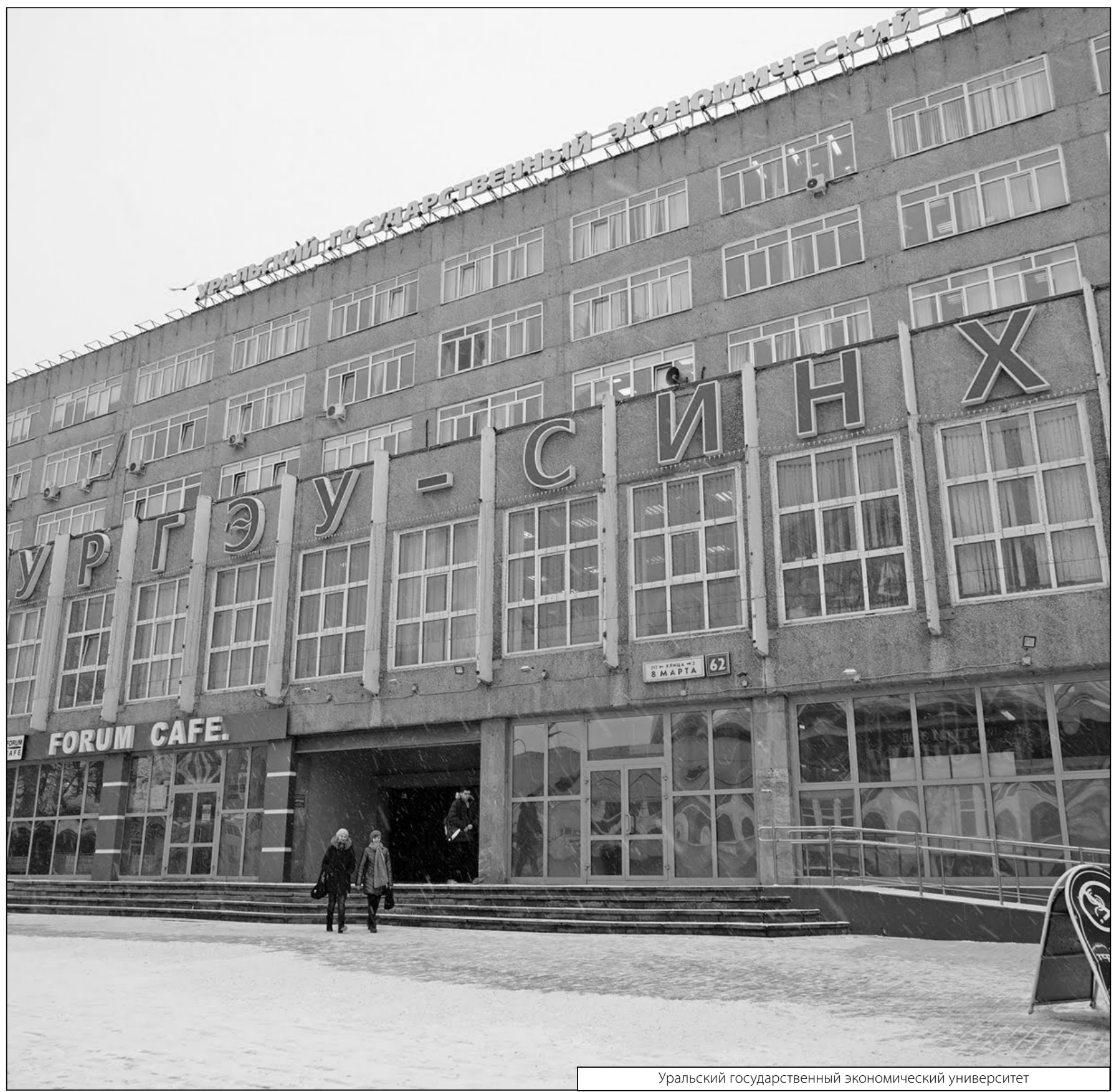

